\title{
Capability of arsonolipids to transport divalent cations: a Pressman cell study
}

\author{
Olga Gortzi a, Pavlos Klepetsanis a, Sophia G. Antimisiaris ${ }^{\text {a,*, }}$, \\ Panayiotis V. Ioannou ${ }^{b}$ \\ a Laboratoty of Pharmaceutical Technology, Department of Pharmacy, University of Patras, Rio 26500, Patras, Greece \\ ${ }^{\mathrm{b}}$ Department of Chemistry, University of Patras, Rio 26500, Patras, Greece
}

Received 2 February 2001; received in revised form 12 April 2001; accepted 17 April 2001

\begin{abstract}
The ability of the newly synthesized arsonolipids (2,3-diacyloxypropylarsonic acids) to transport cations was studied using the Pressman cell. Experimental results demonstrate that arsonolipids are much more efficient carriers of $\mathrm{Ca}^{2+}$ and $\mathrm{Mg}^{2+}$ than natural phosphatidic acid in the Pressman cell experiments. The ability of arsonolipids to transfer $\mathrm{Ca}^{2+}$ is affected by the lipid side chain length in the order: $\mathrm{C}_{12} \gg \mathrm{C}_{14} \cong \mathrm{C}_{16} \cdot \mathrm{Ca}^{2+}$ is transferred faster than $\mathrm{Mg}^{2+}$, suggesting that the latter is more tightly bound to the arsonolipids. The transfer kinetic curves are parabolic for $\mathrm{C}_{12}$, while initially linear with a tendency to reach a steady state for $\mathrm{C}_{14}$ and $\mathrm{C}_{16}$, when the $\mathrm{pH}$ in the donor compartment was 8.3. The transport kinetics for both ions studied were best fitted by an equation derived from saturation kinetics that apply in reversible chemical reactions. The ion transfer rates increased as the $\mathrm{pH}$ in the donor compartment decreased. (C) 2001 Elsevier Science Ireland Ltd. All rights reserved.
\end{abstract}

Keywords: Lipids; Pressman cell; Cation transport; Arsonolipids

\section{Introduction}

The transport of ions such as $\mathrm{Na}^{+}, \mathrm{K}^{+}, \mathrm{Mg}^{2+}$, and $\mathrm{Ca}^{2}+$ across biomembranes is an important phenomenon in living systems (Lehninger, 1971). It plays an essential role in fundamental procedures such as metabolism, transmission of nervous impulses and visual transduction. For

\footnotetext{
* Corresponding author. Tel.: + 30-61-997725; Fax: + 3061-997728.

E-mail address: s.antimisiaris@upatras.gr (S.G. Antimisiaris).
}

therapeutic reasons, the membrane permeability can be enhanced or rendered selective by means of ionophoretic drugs.

The question whether the phospholipid constituents of biological membranes play an active role in the transfer of ions through membranes (in vivo) has not been definitely answered yet. Model experiments showed that acidic phospholipids like cardiolipin and phosphatidic acid (1), can function as transporters of mono- and divalent cations from one aqueous phase (donor compartment) to another (receiving compartment) through an organic liquid phase (Tyson et al., 1976). 




1

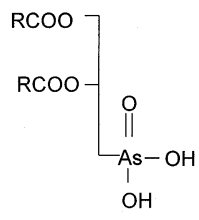

$\underline{\mathbf{2}}$
Arsonolipids (2) (Tsivgoulis et al., 1991) are newly synthesized lipids that have novel characteristics compared with phospholipids or phosphonolipids (Serves et al., 1993). First of all, they are weaker acids compared with phosphatidic acid (for aliphatic arsonic acids, $\mathrm{p} K \mathrm{a}_{1} \sim 4$ and $\mathrm{pKa} \mathrm{a}_{2} \sim 9$ (Doak and Freedman, 1970), while for phosphatidic acid $\mathrm{pKa} \mathrm{a}_{1} \sim 2$ and $\mathrm{p} K \mathrm{a}_{2}>7.5$, in bilayers (Trauble and Eibl, 1974)). Second, the As atom is bigger than the $\mathrm{P}$ atom. However, the most important difference in respect of their in-vivo behavior is probably the fact that the $-\mathrm{AsO}_{3} \mathrm{H}_{2}$ group can be reduced very easily by biologically important thiols (Serves et al., 1995; Timotheatou et al., 1996).

In a recent study (Fatouros et al., 2001), it was found that arsonolipids form tubules $\left(\mathrm{C}_{12}\right)$ or disk-shaped liposomes $\left(\mathrm{C}_{14}, \mathrm{C}_{16}, \mathrm{C}_{18}\right)$, when dispersed alone in aqueous media - under appropriate conditions - while admixed with phosphatidylcholine and/or cholesterol, form more conventional liposomes (arsonoliposomes), in respect of vesicle shape. These latter liposomes can be used either empty (as an As transferring system) or after being loaded with drugs, as drug delivery systems. A particularly interesting aspect of the empty arsonolipid-containing liposomes is their recently observed (in vitro) specific cytotoxicity against several types of cancer cells (Gortzi et al., unpublished results). Indeed, a time- and concentration-dependent decrease in cell viability was observed after cancer cells were incubated with arsonoliposomes, while under the same conditions of incubation normal cells were non-affected.

In view of these recent observations, it is important to have a better understanding of the biophysical properties of arsonolipids. Herein, we report on the ability of arsonolipids (2), with $\mathrm{R}=\mathrm{C}_{11} \mathrm{H}_{23}$ $\left[\mathrm{C}_{12}\right], \mathrm{R}=\mathrm{C}_{13} \mathrm{H}_{27}\left[\mathrm{C}_{14}\right]$, and $\mathrm{R}=\mathrm{C}_{15} \mathrm{H}_{31}\left[\mathrm{C}_{16}\right]$, to transport $\mathrm{Ca}^{2+}$ and $\mathrm{Mg}^{2+}$ through an organic phase using the Pressman cell.

\section{Materials and methods}

rac-Arsonolipids (2), $\mathrm{C}_{12}, \mathrm{C}_{14}$, and $\mathrm{C}_{16}$, were prepared by the one-pot procedure (Serves et al., 1993). Natural phosphatidic acid (PA) was purchased from Lipid Products (Nutfield, UK) and its purity was checked by thin-layer chromatography, as described elsewhere (New, 1990). All other chemicals were of analytical grade and were purchased from Merck (Darmstad, Germany). All organic solvents utilized in this study were also of analytical grade and were purchased from Techline (Dublin, Ireland).

The chloroform used for the kinetic experiments was pre-saturated with methanol and water as described elsewhere (Bligh and Dyer, 1959), in order to minimize the initial long lag-time observed in cation transfer (Tyson et al., 1976). The aqueous phases were pre-saturated with chloroform and methanol.

\subsection{Kinetics of cation transport in the Pressman cell}

The capability of arsonolipids to transport cations was investigated using a liquid membrane system in Pressman reaction cells. Liquid membranes have been studied as models of biological membranes and as a mean of performing chemical separations (Pressman and deGuzman, 1975). A liquid membrane is a liquid or quasi-liquid phase that separates two other liquid phases in which the membrane is immiscible. The Pressman cell that was used in our experiments consists of a hermetically closing glass cylinder $(1.90 \mathrm{~cm}$ internal diameter) that is longitudinally bisected by an internal glass wall (which extends $1.20 \mathrm{~cm}$ above the flat floor of the cell). The organic phase $(6 \mathrm{ml}$ pre-saturated chloroform containing $0.42 \mathrm{mM}$ arsonolipid) was added first. After this, the donor aqueous phase $(2.0 \mathrm{ml})$ containing the appropriate cation as $\mathrm{CaCl}_{2}$ or $\mathrm{MgCl}_{2}$ at $0.42,25$ or $100 \mathrm{mM}$ in $25 \mathrm{mM}$ tetramethylammonium tricine (TMA) buffer ( $\mathrm{pH} 8.3$ or 6.3) was carefully layered on top of the chloroform layer. Finally, the receiving aqueous phase $(2.0 \mathrm{ml})$, consisting of a $25 \mathrm{mM}$ TMA-citrate buffer ( $\mathrm{pH}$ 5.4), was layered on the other side of the organic phase. Each run was 
initiated by gently stirring the organic phase by a magnetic bar. All kinetic runs were performed two or three times at $20 \pm 1^{\circ} \mathrm{C}$.

At specified time intervals, the receiving aqueous phase was gently stirred by the sampling microsyringe and then a $20 \mu$ l aliquot was withdrawn for chemical analysis. The volume taken was replaced by an equal volume of buffer.

\subsection{Determination of cation concentration}

The concentration of $\mathrm{Ca}^{2+}$ and $\mathrm{Mg}^{2+}$ in the samples was determined by atomic absorption spectroscopy. For both cations, calibration curves were prepared by analyzing solutions of known concentrations. Both calibration curves had high correlation coefficients $(R>0.998)$ and low intercepts.

\subsection{Control experiments}

In liquid membrane systems, chemical species may pass from one phase through the membrane to the other phase if they have some solubility in the membrane. This transport may be accomplished by simple diffusion or by 'carrierfacilitated' transport, wherein species are ushered across the membrane by selective 'carrier' molecules that reside in the membrane.

In order to demonstrate that in our experimental set-up, no $\mathrm{Ca}^{2+}$ or $\mathrm{Mg}^{2+}$ is transferred to the receiving aqueous phase by simple diffusion (or, in general, a non-carrier-mediated mechanism), control experiments were performed in which no lipid ('carrier') was included in the chloroform phase. Under all the experimental conditions used throughout the study (cation concentration, aqueous phase $\mathrm{pH}$, etc.) for both cations studied, less than $1 \%$ of the amount initially placed in the donor compartment was transported by simple diffusion.

\subsection{Cation selectivity experiments}

The concomitant transfer of $\mathrm{Ca}^{2+}$ and $\mathrm{Mg}^{2+}$ by the $\mathrm{C}_{14}$ arsonolipid was studied by adding both cations (100 $\mathrm{mM}$ of each one) in the donor phase and following the transfer of both in the receiving phase.

\subsection{Analysis of the kinetics of cation transport}

In all cases, the kinetics of the transport of both cations studied were analysed according to the following final equation:

$C_{\mathrm{B}, t}=\frac{C_{\mathrm{A}, 0}}{2}\left(1-\mathrm{e}^{-2 k t}\right)$

where $C_{\mathrm{A}, 0}$ is the ion concentration initially added in the donor phase, $C_{\mathrm{B}, t}$ is the ion concentration in the receiving phase at time $t$, and $k$ is the rate constant of the ion transport. Eq. (1) can be easily derived by Laplace transformation from the equations that describe a reversible reaction that ends when equilibrium is reached.

Other kinetic approaches (zero, first and second order) applying for non-reversible (one-way) reactions failed to describe the experimental results, since very low coefficients of correlation were obtained.

\section{Results and discussion}

The aim of this study was to investigate whether arsonolipids (2) have, and to what degree, the capability to transport cations through organic bulk phases. In order to investigate this, the Pressman cell apparatus was utilized. Although this system is not realistic, since it cannot predict that ions will be transferred also across biological membranes (in which the lipid molecules are ordered and different mechanisms apply), it was used as a preliminary step that would substantiate the interest for further studies.

In general, the transport of a cation in the Pressman cell involves four steps:

1. Ionization of $\mathbf{2},\left(\mathrm{LH}_{2} \rightarrow \mathrm{LH}^{-}\right)$, desolvation of $\mathrm{M}^{2+}$, and complexation at the donor/organic interface, to give a salt, e.g. $\left(\mathrm{LH}^{-}\right)_{2} \cdot \mathrm{M}^{2+}$ (probably hydrated to satisfy the coordination number of the cation). 
2. Passive mediated diffusion of the $\left(\mathrm{LH}^{-}\right)_{2} \cdot \mathrm{M}^{2+}$ or of an inverted micelle $\left\{\left(\left(\mathrm{LH}^{-}\right)_{2} \cdot \mathrm{M}^{2+}\right)\right.$. $\left.x \mathrm{LH}_{2}\right\}$ through the organic phase.

3. Ionization of the salt, protonation of the $\mathrm{LH}^{-}$, and complexation of the $\mathrm{M}^{2+}$ by the citrate at the organic/receiver interface.

4. Back diffusion of the $\mathrm{LH}_{2}$ from the receiving side to the donor side.

As already mentioned, the transport kinetics of both cations studied in all the experiments performed were analyzed according to Eq. (1). The values of the slope ( $k$, rate constant of the cation transport), intercept and correlation coefficient of the line obtained after log-transformation of Eq. (1), in each case, are presented in Table 1.

In liquid membranes, at the donor/organic interface, the lipid adsorbs the cations and the adsorption can be approximated by the Langmuir adsorption isotherm equation (McLaughlin and Harary, 1976), which predicts that when the concentration of the $\mathrm{M}^{2+}$ is lower than the available absorbing sites $\left(\mathrm{LH}^{-}\right.$molecules) then the $\mathrm{M}^{2+}$ will not be transported to the receiving compartment but will jump from one site to another. This was indeed observed when the concentration of $\mathrm{Ca}^{2+}$ was equal to that of the arsonolipid in the

Table 1

Results of the kinetic analysis of the experimental cation transport results, according to Eq. (1)

\begin{tabular}{llrllll}
\hline Lipid used & Ion studied & $C_{\mathrm{A}, 0}(\mathrm{mM})$ & $k\left(\mathrm{~h}^{-1}\right)$ & Intercept & Correlation coefficient $(R)$ & Figure \\
\hline $\mathrm{C}_{14}$ & $\mathrm{Ca}$ & 100 & $3.95 \times 10^{-4}$ & 11.5 & 0.99433 & Fig. 3A \\
$\mathrm{C}_{14}$ & $\mathrm{Ca}$ & 25 & $2.37 \times 10^{-3}$ & 10.2 & 0.98167 & Fig. 1 \\
$\mathrm{PA}$ & $\mathrm{Ca}$ & 100 & $2.92 \times 10^{-5}$ & 11.5 & 0.96991 & Fig. 3A \\
$\mathrm{C}_{14}$ & $\mathrm{Mg}$ & 100 & $2.33 \times 10^{-4}$ & 11.5 & 0.98413 & Fig. 3B \\
$\mathrm{PA}$ & $\mathrm{Mg}$ & 100 & $6.12 \times 10^{-5}$ & 11.5 & 0.97377 & Fig. 3B \\
$\mathrm{C}_{12}$ & $\mathrm{Ca}$ & 100 & $9.00 \times 10^{-4}$ & 11.5 & 0.97314 & Fig. 2 \\
$\mathrm{C}_{16}$ & $\mathrm{Ca}$ & $3.71 \times 10^{-4}$ & 11.5 & 0.99434 & Fig. 2 \\
$\mathrm{C}_{14}$ & $\mathrm{Ca}(\mathrm{Ca} \& \mathrm{Mg})$ & 100 & $2.14 \times 10^{-4}$ & 11.5 & 0.97862 & Fig. 4 \\
$\mathrm{C}_{14}$ & $\mathrm{Mg}(\mathrm{Ca} \& \mathrm{Mg})$ & 100 & $9.86 \times 10^{-5}$ & 11.5 & 0.98543 & Fig. 4 \\
$\mathrm{C}_{14}$ & $\mathrm{Mg}(\mathrm{pH}$ effect) & 100 & $5.95 \times 10^{-4}$ & 11.5 & 0.97887 & Fig. 5 \\
$\mathrm{PA}$ & $\mathrm{Mg}(\mathrm{pH}$ effect) & 100 & $3.25 \times 10^{-4}$ & 11.5 & 0.97285 & Fig. 5 \\
\hline
\end{tabular}

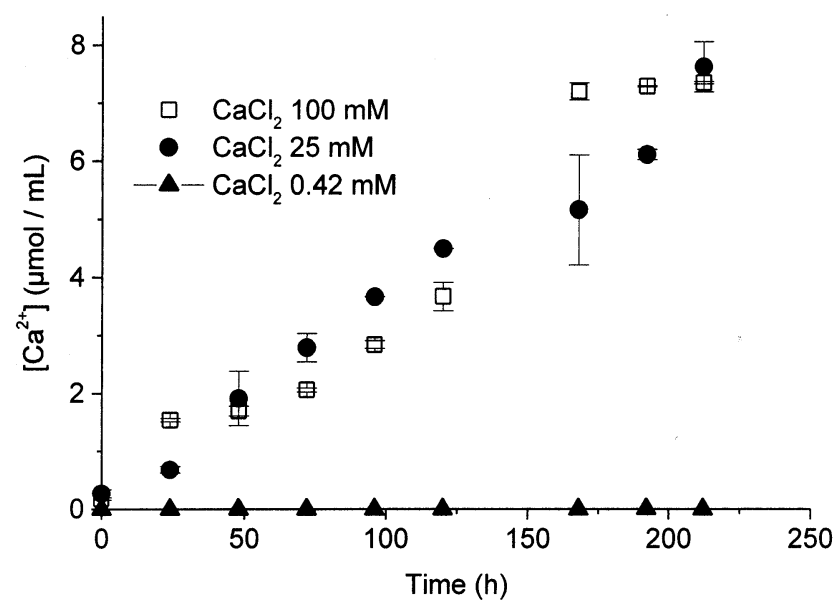

Fig. 1. $\mathrm{Ca}^{2+}$ transfer by arsonolipid $\mathrm{C}_{14}$ : effect of $\mathrm{Ca}^{2+}$ initial concentration in the donor (aqueous phase) compartment. The arsonolipid concentration in the organic phase was $0.42 \mathrm{mM}$. Each point is the mean from at least two experiments, each performed in duplicate, and error bars represent S.D. values. 


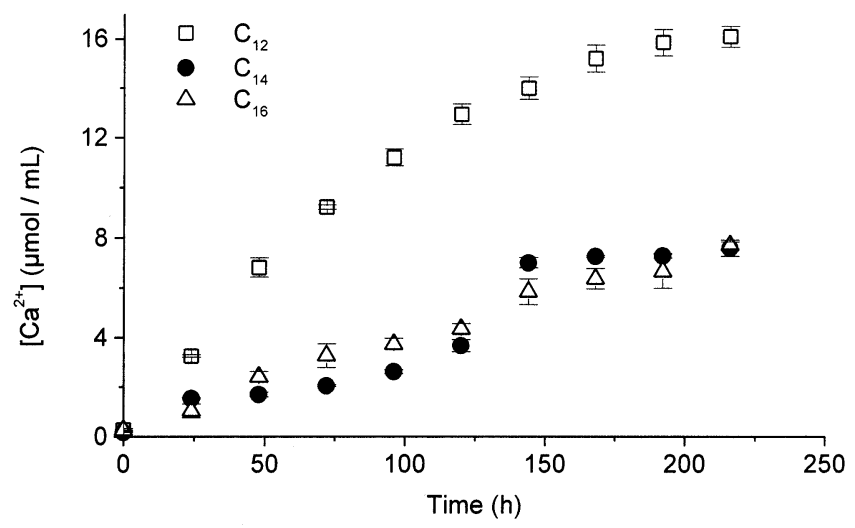

Fig. 2. $\mathrm{Ca}^{2+}$ transfer by arsonolipids: effect of arsonolipid fatty acyl chain length. Initial $\mathrm{Ca}^{2+}$ concentration in the donor compartment was $100 \mathrm{mM}$. The arsonolipid concentration in the organic phase was $0.42 \mathrm{mM}$. Each point is the mean from at least two experiments, each performed in duplicate, and error bars represent S.D. values.

organic phase $(0.42 \mathrm{mM})$, as presented in Fig. 1 (solid triangles in the graph). When the concentration of $\mathrm{Ca}^{2+}$ increased, the transport was initiated and followed initially linear kinetics with a tendency to reach a steady state (saturation). However, the kinetics of $\mathrm{Ca}^{2+}$ transport do not seem to be at all influenced by the increase of $\mathrm{CaCl}_{2}$ concentration in the donor aqueous phase from 25 to $100 \mathrm{mM}$ (Fig. 1). The difference in the transport rate constant calculated in Table 1 for the two cases is due to the large difference in $C_{\mathrm{A}, 0}$, in the two experiments.

The previously demonstrated effect of arsonolipid fatty acyl chain length on physicochemical properties of the lipids (Serves et al., 1993), as well as on the morphology, size and stability of the vesicles they form (Fatouros et al., 2001), prompted us to study the transport of $\mathrm{Ca}^{2+}$ by the $\mathrm{C}_{12}$ and $\mathrm{C}_{16}$ arsonolipids, as well. From Fig. 2, it is evident that the fatty acyl chain length plays an important role in the transfer process. The fact that $\mathrm{C}_{12}$ transports $\mathrm{Ca}^{2+}$ at a much higher rate $\left(k=9.0 \times 10^{-4}\right.$; Table 1) compared with $\mathrm{C}_{14}$ and $\mathrm{C}_{16}$ arsonolipids $\left(k=3.95 \times 10^{-4}\right.$ for $\mathrm{C}_{14}$ and $3.71 \times 10^{-4}$ for $C_{16}$ ) is probably related to the lipid-cation binding strengths. A strong binding will delay the ionization at the organic/receiving phase interface. It is also conceivable that the detachment of the salt from the donor/organic phase interface will also be affected. The simple hyperbola for the $\mathrm{C}_{12}$ lipid implies a well-behaved passive, carrier-mediated, ion-pair transport.

Since the $\mathrm{C}_{12}$ lipid had a very high $\mathrm{Ca}^{2}+$ transport ability, we chose the $\mathrm{C}_{14}$ for further comparative studies. The experimental set-up and conditions used in this study (dimensions of the Pressman cell, temperature, concentration of cations in the donor compartment, stirring rate, and the period of runs), were different from those used previously (Tyson et al., 1976). Therefore, we used natural PA in order to correlate our results with those of others (Tyson et al., 1976).

As presented in Fig. 3, our data demonstrate that the $\mathrm{C}_{14}$ arsonolipid is much more efficient for $\mathrm{Ca}^{2+}$ or $\mathrm{Mg}^{2+}$ transport than natural PA, under identical experimental conditions. Indeed, from the rate constant values calculated in Table 1, it is easily calculated that arsonolipid $\mathrm{C}_{14}$ transports $\mathrm{Ca}^{2}+12.8$ times and $\mathrm{Mg}^{2}+3.8$ times faster than PA. Thereby, the arsonolipids as a class do have a much higher ion-translocating ability compared with acidic phospholipids. This may be due to their higher $\mathrm{p} K \mathrm{a}_{i}$ values and to weaker binding of the $\mathrm{M}^{2+}$ to the $-\mathrm{AsO}_{3} \mathrm{H}^{-}$group, due to the bigger size of As compared with $\mathrm{P}$. In similar previous experiments (Tyson et al., 1976), it was demonstrated that cardiolipin was twice as effective as PA in transporting $\mathrm{Ca}^{2+}$.

In the same previous study, it was also observed that $\mathrm{Ca}^{2+}$ and $\mathrm{Mg}^{2+}$ were transferred by 
PA at the same rate, demonstrating that PA does not show a cation specificity or selectivity (Tyson et al., 1976). In agreement with this previous study, our results also demonstrate that PA transfers the same amounts of $\mathrm{Ca}^{2+}$ or $\mathrm{Mg}^{2+}$ (Fig. 3A,B), although their transfer kinetics differ $(k$ value is double in the case of $\mathrm{Mg}^{2+}$; Table 1) since an induction period was observed for the transfer of $\mathrm{Mg}^{2}+$ (Fig. 3B), a fact difficult to explain. However, the $\mathrm{C}_{14}$ arsonolipid showed a significantly higher ability to transfer $\mathrm{Ca}^{2+}$ versus $\mathrm{Mg}^{2+}$ : at the same time period, it transferred nearly twice as much $\mathrm{Ca}^{2+}$ than $\mathrm{Mg}^{2+}$ (Fig. 3) and the rate constant for $\mathrm{Ca}^{2+}$ transfer was almost double than the constant calculated for $\mathrm{Mg}^{2+}$ (Table 1). This may imply that the strength of binding of $\mathrm{Mg}^{2+}$ to the $-\mathrm{AsO}_{3} \mathrm{H}^{-}$group is higher than that of $\mathrm{Ca}^{2+}$.

In addition to this, when both $\mathrm{Ca}^{2+}$ and $\mathrm{Mg}^{2+}$ are initially placed in the donor phase, the amounts of cation transferred by the $\mathrm{C}_{14}$ arsonolipid were significantly lower (nearly one-half) for both cations (1.7 and 2.3 times lower for $\mathrm{Ca}^{2+}$ and $\mathrm{Mg}^{2+}$, respectively) and, thereby, the ratio of the relative amounts of cations transferred was more or less maintained (Fig. 4). This again implies that the $\mathrm{C}_{14}$ arsonolipid binds $\mathrm{Mg}^{2+}$ stronger than $\mathrm{Ca}^{2+}$, even when both cations are present, the net result being attributed to the fact that there is less 'free' lipid available to transport the cations. Nevertheless, the simultaneous presence of both cations did not affect the transferring
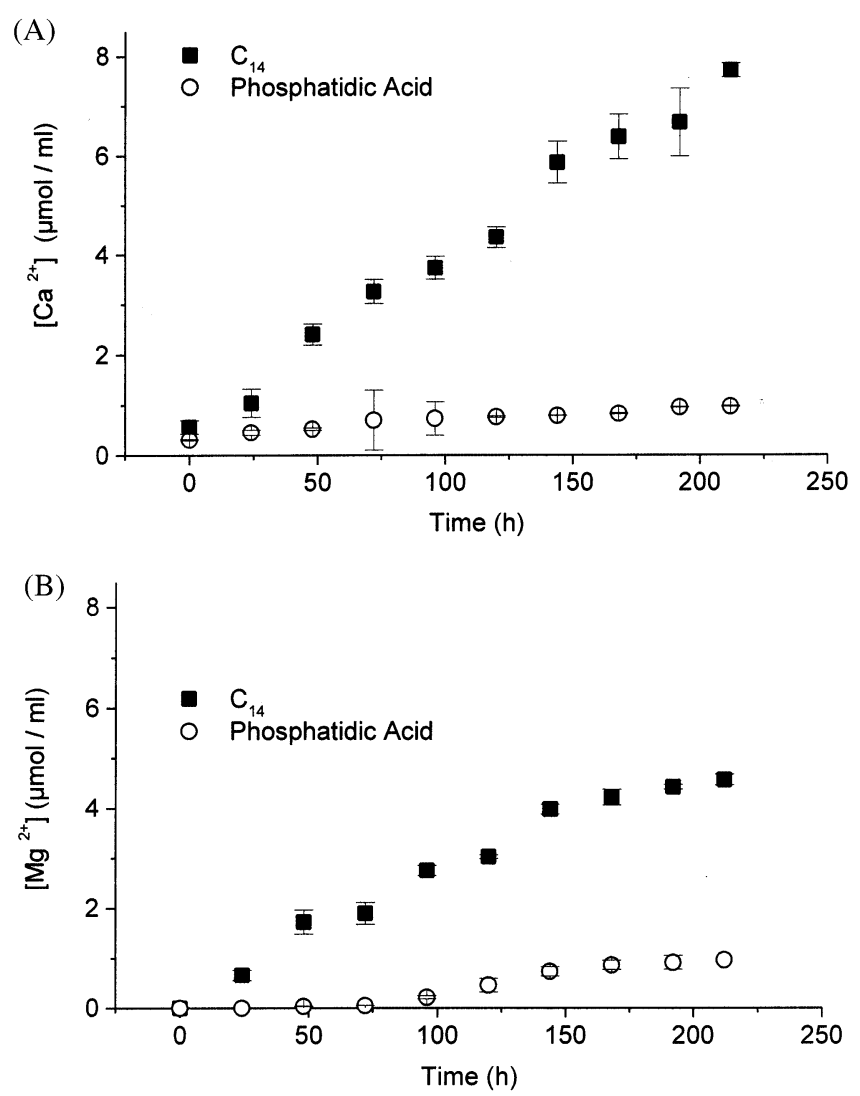

Fig. 3. (A) Kinetics of $\mathrm{Ca}^{2}+$ transport by lipid $\mathrm{C}_{14}$ and PA. The arsonolipid concentration in the organic phase was $0.42 \mathrm{mM}$ and the initial concentration of $\mathrm{Ca}^{2}+$ in the donor compartment was $100 \mathrm{mM}$. Each point is the mean from at least two experiments, each performed in duplicate, and error bars represent S.D. values. (B) Kinetics of $\mathrm{Mg}^{2+}$ transport by arsonolipid C 14 and PA. The lipid concentration in the organic phase was $0.42 \mathrm{mM}$ and the initial concentration of $\mathrm{Mg}^{2}+$ in the donor compartment was 100 $\mathrm{mM}$. Each point is the mean from at least two experiments, each performed in duplicate, and error bars represent S.D. values. 


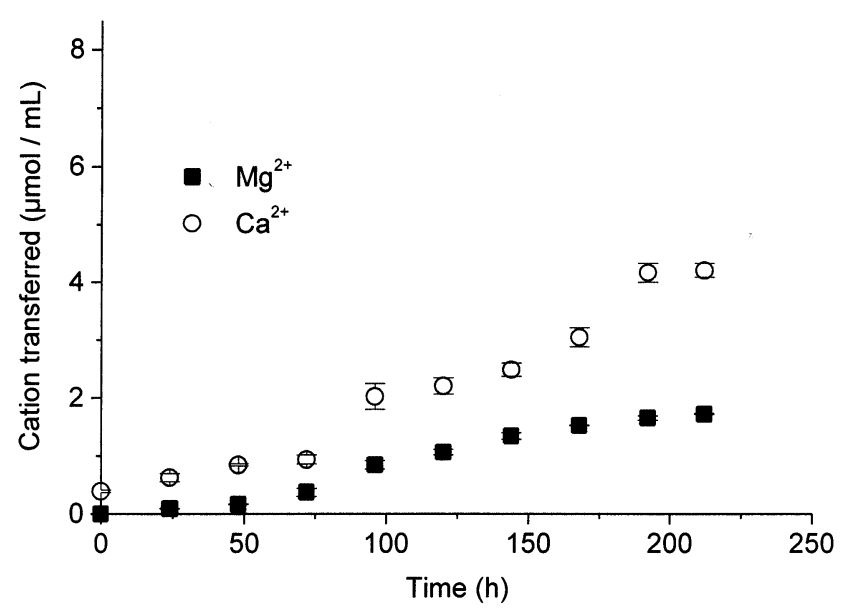

Fig. 4. Selectivity of cation transfer $\left(\mathrm{Ca}^{2+}\right.$ versus $\left.\mathrm{Mg}^{2+}\right)$ by arsonolipid $\mathrm{C}_{14}$. The arsonolipid concentration in the organic phase was $0.42 \mathrm{mM}$ and the initial concentration of both $\mathrm{Ca}^{2+}$ and $\mathrm{Mg}^{2+}$ in the donor compartment was $100 \mathrm{mM}$. Each point is the mean from at least two experiments, each performed in duplicate, and error bars represent S.D. values.

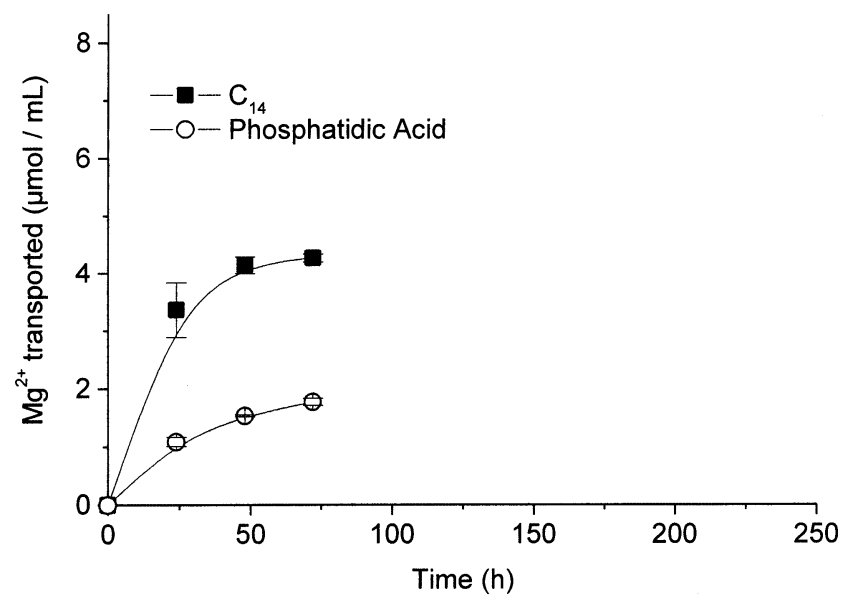

Fig. 5. Effect of $\mathrm{pH}$ of the donor phase on the transport of $\mathrm{Mg}^{2+}$ by arsonolipid $\mathrm{C}_{14}$. The $\mathrm{pH}$ of the donor phase was changed to 6.3 (from 8.3 in all other experiments). The lipid concentration in the organic phase was $0.42 \mathrm{mM}$ and the initial concentration of $\mathrm{Mg}^{2}+$ in the donor compartment was $100 \mathrm{mM}$. Each point is the mean from at least two experiments, each performed in duplicate, and error bars represent S.D. values.

ability of any one cation (no displacement of one cation by the other) as previously demonstrated for cardiolipin (Tyson et al., 1976), which lost $70 \%$ of its ability to transport $\mathrm{Ca}^{2+}$ (in the presence of $\mathrm{Mg}^{2+}$ ).

Another factor that was studied herein, is the $\mathrm{pH}$ of the donor aqueous phase. The effect of the $\mathrm{pH}$ of the donor aqueous phase on transport ability was similar between the $\mathrm{C}_{14}$ arsonolipid and PA. Indeed, a change in $\mathrm{pH}$ from 8.3 to 6.3 had a profound effect on the rate at which both the arsonolipid and PA transferred $\mathrm{Mg}^{2+}$, which was several times higher at $\mathrm{pH} 6.3$ (Fig. 5) compared with that observed at $\mathrm{pH} 8.3$ (Fig. 3B). Moreover, no induction period for the transfer by PA was observed at $\mathrm{pH}$ 6.3. Since at this later $\mathrm{pH}$ both lipids are in the $-\mathrm{MO}_{3} \mathrm{H}^{-}$state, the difference in the transport rates between $\mathrm{pH} 6.3$ and 8.3 
must be attributed to the cation concentration at the donor/organic phase interface. At $\mathrm{pH} 8.3$, its concentration must be lower due to the presence of absorbed $\mathrm{HO}^{-}$ions. On the other hand, in previous experiments with cardiolipin, which has two phosphate di-ester groups, a similar change in the donor phase $\mathrm{pH}$ from 8.3 to 5.4 had no significant effect on the ability of this lipid to transfer $\mathrm{Ca}^{2+}$ (Tyson et al., 1976).

In conclusion, our experiments demonstrate that the arsonolipids (2) have a remarkable ability to transfer $\mathrm{Ca}^{2+}$ and $\mathrm{Mg}^{2+}$ through a liquid apolar organic phase, in which the transferring entity is free to adopt the best conformation.

The kinetics of the cation transport are well described by the kinetics of reversible reactions (Eq. (1)), with initial linear sections that, in some cases, tend to reach a saturation or else equilibrium point (as in the case of $\mathrm{C}_{12}$ arsonolipid; Fig. 2). Slight hydrolysis of the arsonolipids (2) cannot account for the shape of these curves because they are quite stable (Kordalis and Ioannou, 2000). Similar kinetics (initially linear with a tendency to reach a final saturation point) have previously been observed in amino acid transport experiments (Behr and Lehn, 1975).

Aspects related to the binding affinity, the stoichiometry and the nature of the complexes formed during the ion transport cannot be answered at the moment. In order to substantiate the speculation that arsonolipids could have ionophoretic effects in membranes, further studies are required that will prove these lipids can indeed catalyse the transfer of cations across bilayers. Indeed, a more realistic model for the study of the ionophoretic capability of lipids is the bilayer in uni- or multilamellar vesicles. Using multilamellar vesicles, it was shown that natural PA (but not dipalmitoyl-PA) added externally to liposomes (Serhan et al., 1981, 1982), or when present in the vesicle membrane (Serhan et al., 1982) can transport $\mathrm{Ca}^{2+}$, as well as dioleyl-PA when present in the membrane of unilamellar liposomes (Smaal et al., 1985). However, when cardiolipin was incorporated into multilamellar vesicles, no entry of $\mathrm{Ca}^{2+}$ into the vesicles was measured (Serhan et al., 1981, 1982).
We have recently prepared unilamellar and multilamellar vesicle containing arsonolipids that were demonstrated to have negative zeta potential values, linearly correlated with the arsonolipid content of their membrane (Fatouros et al., 2001). In addition, in very recent studies (Gortzi et al., unpublished results) the presence of $\mathrm{Ca}^{2+}$ has been demonstrated to affect the vesicle zeta potential substantially more in vesicles that have higher arsonolipid contents. Although very preliminary, these latter results may have some connection with the effect of cations on the organization of arsonolipids in membranes, as demonstrated by others studying the interactions of proteins with membranes (Murray et al., 1999). Furthermore, in addition to the results of the present study, they may serve as an additional indication that arsonolipids may indeed have ionophoretic ability in membranes. Therefore, it will be interesting to continue our studies with arsonolipids using vesicle models.

\section{Acknowledgements}

This work is in part a requirement for the M.Sc degree of O.G, and has been supported by a research grant (PENED 95) from the Greek General Secretariat of Research and Technology, Athens, Greece.

\section{References}

Behr, J.-P., Lehn, J.-M., 1975. Transport of amino acids through organic liquid membranes. J. Am. Chem. Soc. 95, 6108-6110.

Bligh, E.G., Dyer, W.J., 1959. A rapid method of total lipid extraction and purification. Can. J. Biochem. Physiol. 37, 911-917

Doak, G.O., Freedman, L.D., 1970. Organometallic Compounds of Arsenic, Antimony, and Bismuth. Wiley, New York, pp. 26-32.

Fatouros, D., Gortzi, O., Klepetsanis, P., Antimisiaris, S.G., Stuart, M.C.A., Brisson, A., Ioannou, P.V., 2001. Preparation and properties of arsonolipid containing liposomes. Chem. Phys. Lipids 109, 75-89.

Kordalis, N.L., Ioannou, P.V., 2000. Synthesis of arsinolipids: non-isosteric analoques of phospholipids. Appl. Organometal. Chem. 14, 273-280. 
Lehninger, A.L., 1971. Biochemistry. Worth, New York, pp. 605-627.

McLaughlin, S., Harary, H., 1976. The hydrophobic adsorption of charged molecules to bilayer membranes: a test of the applicability of the Stern Equation. Biochemistry 15, 1941-1948.

Murray, D., Arbuzova, A., Hangyas-Mihalyne, G., Gambhir, A., Ben-Tar, N., Honig, B., McLaughlin, S., 1999. Electrostatic properties of membranes containing acidic lipids and adsorbed basic peptides: theory and experiment. Biophys. J. 77, 3176-3188.

New, R.R.C., 1990. In Liposomes: A Practical Approach (R.R.C. New, Ed.), pp. 134 and 255, IRL Press Oxford University Press, Oxford.

Pressman, B.C., deGuzman, T.N., 1975. Biological applications of ionophores: theory and practice. Ann. NY Acad. Sci 264, 373-386.

Serhan, C., Anderson, P., Goodman, E., Dunham, P., Weissmann, G., 1981. Phosphatidate and oxidized fatty acids are calcium ionophores. Studies employing arsenazo III in liposomes. J. Biol. Chem. 256, 2736-2741.

Serhan, C.N., Fridovich, J., Goetzl, E.J., Dunham, P.B., Weissmann, G., 1982. Leukotriene B4 and phosphatidic acid are calcium ionophores. Studies employing arsenazo III in liposomes. J. Biol. Chem. 257, 4746-4752.
Serves, S.V., Sotiropoulos, D.N., Ioannou, P.V., Jain, M.K., 1993. One pot synthesis of arsonolipid via thioarsenite precursors. Phosphorous, Sulfur and Silicon 81, 181-190.

Serves, S.V., Charalambidis, Y.C., Sotiropoulos, D.N., Ioannou, P.V., 1995. Reaction of arsenic (III) oxide, arsenous and arsenic acids with thiols. Phosphorous, Sulfur and Silicon 105, 109-116.

Smaal, E.B., Mandersloot, J., de Kruijff, B., de Gier, J., 1985. Essential adaptation of the calcium influx assay into liposomes with entrapped arsenazo III for studies on the possible calcium translocating properties of acidic phospholipids. Biochim. Biophys. Acta 816, 418-422.

Timotheatou, D., Ioannou, P.V., Scozzafava, A., Briganti, F., Supuran, C.T., 1996. Carbonic anhydrase interaction with lipothioarsenites: a novel class of isozymes I and II inhibitors. Metal-Based Drugs 3, 263-268.

Trauble, H., Eibl, H., 1974. Electrostatic effects on lipid phase transitions: membrane structure and ionic environment. Proc. Natl. Acad. Sci. USA 71, 214-219.

Tsivgoulis, G.M., Sotiropoulos, D.N., Ioannou, P.V., 1991. 1,2 Dihydroxypropyl-3-arsonic acid: a key intermediate for arsonolipids. Phosphorus, Sulfur and Silicon 57, 189-193.

Tyson, C.A., Zande, H.V., Green, D.E., 1976. Phospholipids as ionophores. J. Biol. Chem. 251, 1326-1332. 